\title{
A science tax?
}

Seoul

THE world's scientists, who often feel they do not have enough money to support their research, will certainly appreciate an idea making the rounds in the South Korean government - a tax levied specifically to raise research funds for science and technology.

As Korea tries to catch up with the technology of the advanced nations of the world, government bureaucrats are giving serious consideration to the introduction of a 'science tax'. Although such a tax is unprecedented, the general scheme of assessing taxes for specific purposes is well established - in the past, the South Korean govern-

at about 2 per cent of a healthy GNP, which the government officially placed at about $\$ 273,000$ million for 1991 . And last week, in mapping out Korea's seventh five-year economic plan, for 1992-1996, a committee chaired by Prime Minister Chung Won-shik estimated that science and technology investment will rise to 3.2 per cent of GNP, or 11.5 million million won $(\$ 15,300$ million) by 1996 .

These figures should be treated with some caution because much of the increase is due to a surge in capital spending rather than to increased operating expenses for research. Private conglomerates such as Hyundai and Samsung have been funding the construction of research institutes, and this construction boom is expected to continue into the 1990s. Also, the government consistently tends to underestimate GNP in order to maintain favourable lending rates with the World Bank.

Nevertheless, South Korea does now have a substantial infrastructure of new and well-equipped research institutes in both the government and private sector, and the population of doctoral- and masters-level engineers and scientists is growing rapidly. At present, the country has about 50,000 researchers (one-tenth that of Japan), and the government's plans call for this number to be tripled by early next century. This would bring the percentage of researchers in the total population (currently 42 million) up to a level comparable with that of advanced nations, such as the United States and Japan.

The G-7 project forms a key part of the government plans for expansion. With a proposed budget of about $\$ 7,000$ million over nine years (1992-2000), the project will support the development of seven advanced technologies - semiconductor memory chips, Integrated Services and Data Networks (ISDN) for telecommunications, high-definition television (HDTV), electrical vehicles, intelligent computers, new antibiotics and chemicals for agriculture, and advanced, fully auto- ment has put extra taxes on corpora tions and its citizens to raise funds for defence. So why not, the bureaucrats ask, have a tax to aid Korea's bid to catch up with the technology of Japan and the West?

Among those monitoring science policy in Seoul, the science tax is the talk of the town, but no one can say whether it will ever be levied. It is bound to be unpopular with the general public, and government researchers say that one thing is certain: no attempt to introduce the new tax will be made until, at the earliest, after the general election for the national assembly early next year. David Swinbanks

mated manufacturing systems.

A second part of the project will concentrate on the development of basic technology that is further from the market. Again seven areas are targeted: new materials, next-generation transportation systems, biotechnology, 'environment friendly' technology, new clean energy sources, advanced atomic reactors and human interface technology based on "user friendly' electronics and robotics.

If all goes according to plan, Korea will have developed 256-megabit dynamic random access memory (DRAM) chips by 1996 and 1-gigabit chips by 2000. (Korea already has its own domestically developed 16-megabit chips.) HDTV monitors compatible with Japanese and European systems are scheduled to become available in 1993, and HDTV flatscreen displays by 1997 . Electrical vehicles would be commercialized by 1996, a neuro-computer by 1997 , and ISDN by 2000 .

Much (50 to 70 per cent) of the research will be carried out by institutes affiliated with the Ministry of Science and Technology, particularly the Korean Institute of Science and Technology (KIST) in Seoul and affiliated KIST institutes and the Korean Advanced Institute of Science and Technology in Daeduck science town. But private industry will also make a substantial contribution, and so will the new Korean Academy of Industrial Technology, an organization that coordinates and funds near-market joint research between government, industry and academia.

Whether the project will achieve the full level of funding proposed remains open to question. One Western science officer in Seoul says he always divides figures quoted by Korean government officials by three to arrive at a more realistic estimate of what is actually going on. It is clear, however, that the G-7 project will go ahead and Korea is determined to go on the fast track to try to catch up with the most advanced nations of the world.

David Swinbanks

\section{UK primate research under scrutiny}

\section{London}

A NUMBER of published British research studies involving primates should not have been licensed under existing animal welfare legislation, according to the Scottish pressure group Advocates for Animals. The group, which last year exposed serious breaches of animal welfare legislation at the National Institute for Medical Research of the Medical Research Council (MRC) (see Nature $345 ; 190 ; 1990$ ), this week released a report detailing 13 research papers published since 1987 derived from work that Advocates for Animals believe should not have received Home Office approval.

Les Ward, director of Advocates for Animals, said the aim of the report is to ensure that British primate researchers adhere to UK animal experimentation legislation, as overhauled in $\mathbf{1 9 8 6}$. The $\mathbf{1 9 8 6}$ Act requires that the Home Secretary not grant a project licence for work involving primates unless no other species are suitable for the research, or if it is impractical to obtain animals from other species.

Ward questions whether this requirement was met for several of the research projects examined in the report. Advocates for Animals also charge that some of the research was repetitive of previous experiments, and that in some cases the Home Office failed adequately to balance the likely suffering of the animals concerned against the expected benefits of the research. The group wants the Home Secretary to investigate why the named research projects were approved, and for the Animal Procedures Committee (a panel of independent experts which advises the Home Office) to review all current British primate research. On Monday, the Home Office said it would look into Advocates for Animals' specific allegations before deciding whether to examine British primate research in general.

Unlike its previous report on work at the National Institute for Medical Research, which involved clear breaches of the 1986 Act, Advocates for Animals' latest charges will be difficult to address. The issues in question - whether the use of primates was essential, whether the suffering outweighed the gain in scientific knowledge, and the degree of overlap with previous work - depend on subjective judgements, where the opinions of researchers and of animal welfare groups will diverge. "You can't give somebody a cost-benefit equation in which to plug in the parameters," says MRC secretary Dai Rees, whose organization provided funding for more than half of the projects named by Advocates for Animals. Nevertheless, he says the MRC intends to investigate the charges fully. Peter Aldhous 